\title{
TERRITORIO Y POBLAMIENTO EN LA FRONTERA NORORIENTAL GRANADINA. LA HOYA DE BAZA Y EL ALTIPLANO ${ }^{1}$
}

\author{
Antonio Malpica Cuello \\ Universidad de Granada
}

\section{RESUMEN}

La investigación sobre las formas materiales de vida y la organización del territorio de un espacio fronterizo, el situado en el extremo nororiental del reino nazarí de Granada, obliga a un examen de las fuentes escritas y un análisis predominantemente arqueológico. A partir de ellos, dentro de la Arqueología del Paisaje, hemos podido estudiar los asentamientos humanos, en su mayor parte fortificados, la estructuración de las actividades agrícolas y ganaderas. Hemos visto así que el distrito al norte de la ciudad de Baza tenía una gran capacidad productiva, más allá de la agricultura irrigada, y que estaba, además, integrada en su condición de tierra de frontera.

Palabras clave: Arqueología Medieval, Arqueología del Paisaje, Asentamientos, Agricultura y Ganadería, Reino de Granada, Altiplano de Baza.

\section{SUMMARY}

To research the material forms of life and territory organisation of a border area, in this case that of the northeastern end of the Nasrid kingdom of

$\overline{1}$ Este trabajo se ha realizado en el marco del proyecto I+D (HAR2011-24767), titulado «Sal y ganadería en el reino de Granada», del que es investigador principal el firmante de este artículo. Nuestro agradecimiento a Guillermo Garcia-Contreras Ruiz y Sonia Villar Mañas, integrantes del equipo del citado proyecto, por su colaboración inestimable en los trabajos de campo. 
Granada, it was necessary to examine the written sources and to conduct an analysis that was mostly archaeological. Based on these approaches and remaining within landscape Archaeology, we were able to study human settlements, mostly fortified ones, as well as the structuring of agricultural and livestock activities. We thus observed that the district north of Baza city had a large productive capacity beyond irrigated agriculture, and that it was integrated as a border land.

Keywords: Medieval Archaeology, Landscape Archaeology, Settlements, Agriculture and Livestock, Kingdom of Granada, Altiplano de Baza.

\section{INTRODUCCIÓN}

En los últimos años la investigación sobre los paisajes históricos ha generado una literatura científica muy notable. Es cierto que la investigación a veces ha carecido de discusiones de contenido teórico, en tanto que en otras los análisis no se han concretado. No es cuestión de entrar aquí en un estudio más o menos crítico de esta tendencia historiográfica en el medievalismo español ${ }^{2}$. Nosotros mismos hemos llevado a cabo una valoración de la investigación que se ha llevado a cabo en el reino de Granada ${ }^{3}$.

De todos modos, conceptos como el de paisaje y territorio permiten integrar diferentes técnicas para conseguir entender el proceso de las formaciones sociales en espacios que organizan en su propio beneficio. El resultante visible del mismo es el paisaje, que es una acumulación de realidades con distinta funcionalidad, pero la configuración en conjuntos espaciales es fundamental.

Los elementos que los integran y organizan y que se pueden identificar hacen posible entender la relación entre los seres humanos, agrupados socialmente, y la naturaleza en la que se insertan. Las variabilidades son importantes, pero también cabe decir que una sociedad se ve a sí misma y se refleja en su paisaje y en su territorio, como es percibida de manera diferenciada por otras sociedades. En el caso de confrontación suele producirse una colisión de intereses y se marcan aún más las diferencias entre ellas.

2 Una discusión general en MARTÍNEZ VÁZQUEZ, Luis, «Senderos que se bifurcan. Los estudios de paisaje en el medievalismo peninsular», en MARÍN LÓPEZ, Rafael (ed.), Homenaje al Profesor Dr. D. José Ignacio Fernández de Viana y Vieites, Granada, 2012, pp. 263-277.

3 MALPICA CUELLO, Antonio, «El estudio del paisaje y la práctica de la arqueología del paisaje en el antiguo reino de Granada», en MALPICA CUELLO, Antonio (ed.), Análisis de los paisajes históricos. De al-Andalus a la sociedad feudal, Granada, 2009, pp. 17-35. 
De todo esto último queremos hablar al analizar un caso concreto, el del espacio fronterizo del noreste del reino nazarí, articulado, como se verá, por la ciudad de Baza, pero dividido en varios subconjuntos con una entidad propia. Hemos elegido este conjunto territorial, mejor dicho, el subconjunto central, el más directamente relacionado con la mencionada ciudad bastetana, porque queremos ver si el peso de la frontera determinó una organización de los asentamientos y del territorio que rige distinta de la que se da en otras áreas del reino nazarí.

En principio no parece que así fuera, porque los espacios irrigados, ligados muy directamente a los núcleos poblados, son fundamentales, pero no es menos cierto que el peso del agroecosistema de regadío no es único, lo que supone que consideremos la economía agraria en su globalidad, interviniendo otras actividades económicas que suelen tener poca consideración en la investigación del mundo rural nazarí, cuales son los cultivos extensivos de secano, a veces con riegos eventuales, pero muy concentrados y, especialmente, la ganadería. Esta última nos obliga a analizar los espacios naturales, el monte mediterráneo que, como bien es sabido, ha de ser visto siempre como un espacio penetrado y, en algunos casos, adaptado por los hombres a lo largo de la historia. También, al tratarse precisamente de ganados rumiantes, hace necesario fijarse en los sistemas de aprovisionamiento de sal, producto muy necesario, incluso imprescindible para ellos.

La relación entre todas las actividades económicas, de acuerdo con los elementos visibles en el paisaje de este territorio y sus partes, más o menos diferenciadas, hay que discernirla y señalarla de manera que sea inteligible y sirva para explicar la forma de organizarse la sociedad nazarí en esta área de frontera.

Con todo, aun cuando hay similitudes notables, la importancia de los ganados, que ha tenido siempre un peso grande en el altiplano de Baza y sus sierras vecinas, pone de manifiesto una economía extensiva al lado de otra intensiva. Aquella sin duda fue favorecida tras la conquista castellana.

Es más, la fortificación de los núcleos habitados es otra característica digna de destacar. Se explica por el empuje de los castellanos del otro lado de la frontera, pero surge de necesidades anteriores que intentaban organizar el territorio y ordenar la comercialización del excedente agrario y su fiscalidad. No obstante este es un tema en el que la investigación habrá de profundizar, porque la calificación de un asentamiento no puede hacerse sólo a partir de si está amurallado o no, sino por la configuración que tiene intramuros y las relaciones que mantiene con otros núcleos. Advirtamos, además, que en otras áreas no propiamente fronterizas también se dio ese proceso de fortificación, 
siendo una característica casi general a todo el reino en torno a mediados del siglo XIV que tuvo como consecuencia la creación de nuevas estructuras defensivas y la adaptación de las anteriores.

En este trabajo concreto no es posible solucionar todas las cuestiones apenas enunciadas, sólo queremos que se comprenda la necesidad de estudiar las actividades económicas en cada conjunto territorial. De esa manera será posible una mayor comprensión de ellos, como será inteligible los procesos de configuración de los asentamientos en su espacio físico. Surge así una dinámica propia de la arqueología del paisaje que, según creemos, es la que nos da la información requerida para hacer los análisis propuestos. Se basa no sólo en la consulta de una abundante documentación de archivo, sino también e incluso de forma principal en el reconocimiento del territorio, que es, desde nuestro personal punto de vista una tarea primordial. No ha sido fácil, ya que la existencia de tres elementos bien discernibles (espacios de agricultura irrigada por lo común en el fondo de los valles, altiplano y áreas de montaña) obligan a un examen diferenciado en cada uno de ellos. Al tratarse, sin embargo, de una zona en la que la alteración de los últimos tiempos, visible en otras muchas, ha sido menor, la afectación de los paisajes no ha mermado su capacidad de análisis dentro de las formas de vida tradicionales. En ella las modificaciones suelen ser acumulativas y posibles de leer y entender.

\section{EL DISTRITO DE BAZA}

Tres áreas configuran el paisaje de la zona de Baza y su territorio. En los valles encontramos cursos de aguas que permiten la puesta en valor de las tierras, gracias a la irrigación. En el altiplano hay unas condiciones esteparias que pueden ser en ciertos casos fruto directo de la acción humana. Existe una orla montañosa que cierra este conjunto y que permite hablar de un paisaje de montaña en algunos casos.

Es así como encontramos un territorio en el que conviven la agricultura intensiva gracias a la instalación de un agroecosistema irrigado, fruto de un opción económica que ha vivificado tierras no demasiado aptas para el cultivo, con unos espacios naturales, a veces obra de las sociedades que los han ocupado, que podemos considerar ciertamente propios de un sistema estepario. En ellos la agricultura es muy extensiva y sólo se suele dar en determinados puntos en los que hay una cierta humedad y permite suavizar unas condiciones térmicas que suelen ser extremas. Como fruto de una explotación agrícola en cierto modo excesiva, de acuerdo, claro está con las condiciones ambientales de partida. Es lo que se puede considerar en el caso 
particular que tratamos de estepa ibérica. La hoya de Baza, en efecto, tiene en sus partes altas, que alcanzan los $800 \mathrm{~m}$ de media, suelos pobres y salinos en donde se da una vegetación de matorral. Como ya se ha dicho, rodeando todo el conjunto hay una serie de sierras que le confieren un carácter especial a este territorio. No lo denominamos, como suelen hacer algunos autores cuando hablan de otras áreas granadinas, «singular», porque los paisajes granadinos no se pueden reducir a un único esquema, sino que cuentan con una gran diversidad, siendo mayores las diferencias entre ellos que las similitudes, de manera que todos podrían ser denominados con ese epíteto. En algunos puntos, se dan alturas por encima de los $2000 \mathrm{~m}$.

Es de ese modo como se da la posibilidad, comprobada por los trabajos de campo que venimos realizando y por el análisis de la documentación y de las fuentes escritas, de establecer una economía agrícola y ganadera que trasciende la sempiterna irrigación andalusí, que, por lo demás, es fundamental para entender la vida en estas tierras. En principio, las condiciones climáticas son las propias de una estepa, con unas precipitaciones bajas (de $325 \mathrm{~mm}$ a $350 \mathrm{~mm}$ anuales), y, además, se concentra en pocos días al año; en los años secos puede descender de $200 \mathrm{~mm}$ a $250 \mathrm{~mm}$. Sin embargo, en algunas montañas de sus alrededores es el doble, pues llega de $600 \mathrm{~mm}$ a $700 \mathrm{~mm}$. De esa manera la falta de agua en los terrenos del altiplano se compensan con la existencia de cursos de agua que descienden de las montañas. En ellas, por otra parte, encontramos prados húmedos, que permiten que el ganado acuda en verano a ellos, como se percibe por poner solo un ejemplo, en los llamados Prados del Rey, a más de 2000 m, en la Sierra de Baza.

En principio, a tono con esa escasa precipitación tenemos unos paisajes que marcan claras diferencias entre los que pueden beneficiarse del agua dulce y aquellos otros que sólo reciben cantidades exiguas que, por si fuera poco, se salinizan en los criptohumedales, esenciales para la economía de la zona en época andalusí, que hay en la parte elevada del altiplano. Si bien en los primeros se concentran las explotaciones irrigadas que esmaltan todo el conjunto en el entorno de los núcleos habitados, las alquerías de tiempos nazaríes, algunas de las cuales han desaparecido, pero que permanecen en su mayor parte, en los espacios esteparios encontramos una riqueza que no se suele reparar en ella, la posibilidad de criar un ganado abundante y que paste libremente, con la posibilidad añadida de subir a la montaña a disfrutar de abundantes y ricos pastos de verano, en ciertos casos verdaderos prados húmedos, formados de manera natural, pero también por la acción humana. 
De esta cuestiones cabe hablar en el presente trabajo, para poner de relieve aspectos hasta ahora no considerados importantes. La primera cuestión a reseñar es que nos referimos a un espacio fronterizo durante todo el reino nazarí (siglos XIII a XV), con condiciones que se podrían considerar poco favorables en cuanto al medio físico para ser ocupado por un número importante de núcleos y habitantes. Y, sin embargo, no fue así en ese período, pese a la realidad de sus condiciones naturales y a la presión que ejercían los poderes castellanos del otro lado de la frontera. Tenemos, pues, que, aprovechando al máximo las posibilidades que tenía la sociedad nazarí, heredera directa de la andalusí, creó un espacio y unos paisajes que eran productivos e incluso los podemos considerar altamente productivos. En ese sentido, son singulares, pero también se asemejan a los de otras áreas del reino de Granda.

En todo el conjunto territorial se observa lo que venimos diciendo. Pero antes hemos de definirlo de manera elemental. Situado en el extremo noriental del reino, Baza es el centro principal que rige un amplísimo distrito. En él podemos distinguir diferentes subconjuntos: -El más oriental, en donde se ubican los Vélez (Rubio y Blanco), y los asentamientos fortificados de Xiquena y Tirieza, en las puertas del territorio lorquino, en manos castellanas y que era el centro castellano de esa parte de la frontera; -el que podríamos denominar propiamente central, con Baza, la Madinat Basti de las fuentes árabes, como punto fundamental de control y, sobre todo, de relación de un amplio espacio cercano y menos cercano, todo él poblado de asentamientos en su casi totalidad fortificados, seguramente por el creciente peligro de la frontera, pero estamos seguros que no sólo por eso, sino también por la necesidad de centralizar el excedente productivo de las alquerías y su «realización» económica. Es algo que se comprueba en muchas otras áreas de la frontera nazarí-castellana y que hemos estudiado en otro lugar ${ }^{4}$. Finalmente podríamos hablar del subconjunto que se hallaba en el área más noroccidental, que cayó en el siglo XIV en manos castellanas, articulada en torno a Quesada y en donde se integraba el piedemonte de su sierra en contacto con el altiplano.

En este presente trabajo nos centraremos, sin embargo y de manera principal, en el subconjunto central, que es en donde hemos investigado más a fondo básicamente, aunque no de forma exclusiva, a niveles arqueológicos.

4 MALPICA CUELLO, Antonio, «Las villas de la frontera granadina. ¿Ciudades o alquerías fortificadas?», en CRESSIER, Patrice (Ed.), Castrum 8. Le château et la ville. Espaces et réseaux (VI-XIII siècle), Madrid, 2008, pp. 151-173. 


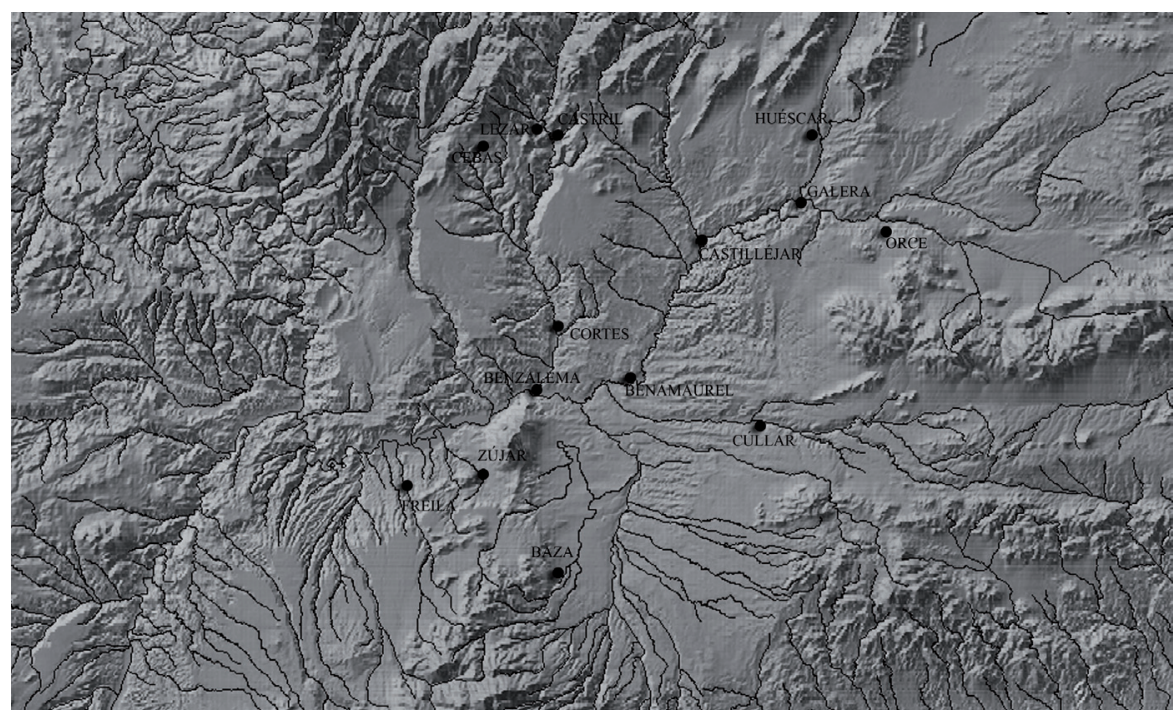

Figura 1. Alquerías del distrito de Baza.

Cuando se produjo la conquista castellana a finales de 1489, con avatares anteriores que no vamos a recoger de manera precisa, los nuevos señores nos dan un referencia concreta, breve pero interesante, sobre los asentamientos que van a ocupar. Así en un documento conservado en el Archivo General de Simancas $^{5}$, que nos ha servido para elaborar un trabajo precedente ${ }^{6}$, señalábamos los aspectos principales de cada núcleo y de sus posibilidades económicas desde la perspectiva fiscal castellana. En el cuadro que a continuación recogemos, elaborado a partir del citado documento, se pueden percibir la «cualificación» de las alquerías del distrito bastetano:

5 Archivo General de Simancas, Diversos de Castilla, lib. 44, fol. 24.

6 MALPICA CUELLO, Antonio, «Paisaje y poblamiento del espacio fronterizo nororiental del reino nazarí de Granada», en JIMÉNEZ PUERTAS, Miguel y MATTEI, Luca (eds.), El paisaje y su dimensión arqueológica. Estudios sobre el sur de al Península Ibérica en la Edad Media, Granada, 2010, pp. 17-53. Con anterioridad fue utilizado por ALFARO BAENA, Concepción, «La hoya de Baza: transformación de la frontera tras la conquista cristiana», Revista del Centro de Estudios Históricos de Granada y su Reino, 7 (1993), pp. 41-66. 
Relación de vecinos y valor agrícola y ganadero de alquerías del distrito de Baza

\begin{tabular}{|l|l|l|}
\hline Alquería & Vecinos & Valor agrícola y/o ganadero \\
\hline Cúllar & 100 & $600 \mathrm{fs}$. pan \\
\hline Freila & 30 & $100 \mathrm{fs}$. pan \\
\hline Galera & 200 & $1000 \mathrm{fs}$. pan/18.000 mrs. ganado \\
\hline Orce & 100 & $800 \mathrm{fs}$. pan/12.000 mrs. ganado \\
\hline Castilléjar & 30 & $200 \mathrm{fs}$. pan/s.e. derecho ganado \\
\hline Benzalema & Despoblada & Buena tierra/buenos términos \\
\hline Cortes & Despoblada & Buena tierra \\
\hline Castril & Despoblada & $\begin{array}{l}100 \mathrm{fs}, \text { pan/240 cabezas ganado (1 de } 12,0 \\
\text { sea } 20.000 \text { cabezas en su sierra) }\end{array}$ \\
\hline
\end{tabular}

Hay que advertir que los datos son exiguos y, además, no aparecen otros núcleos que necesariamente incrementarían el valor del conjunto territorial. Es el caso de las alquerías de Benamaurel y Zújar, próximas a la ciudad de Baza, otras próximas a Castril (Cebas y Lezas) y Huéscar, estas últimas muy cerca de la frontera, teniendo Huéscar una entidad similar a la de una «villa», es decir, superior a la de una alquería.

Llama la atención la capacidad productiva de Galera, que aparece en un pleito posterior a la conquista castellana ${ }^{7}$ con una preeminencia notable con respecto a los demás asentamientos. Se calculan 1000 fanegas de pan y 18000 maravedís que podrían rentar los derechos del ganado. Le sigue Orce, que está muy próxima (800 fs. y 12000 mrs., respectivamente). Por debajo está Cúllar que tenía 600 fs. de pan. Muy lejos en cuanto a los rendimientos de cereal están Castilléjar (200 fs.) y Freila y Castril (100 fs. cada uno). Este último tiene una capacidad de herbaje para el ganado importante (20000 cabezas se podrían alimentar en su sierra).

Estos cálculos nos dan un aproximación, ya que nada se dice de otras alquerías que se recogen (Benzalema y Cortes), aunque se señala de ambas que tienen buenas tierras y de la primera buenos términos, ni se mencionan algunas más.

Una cosa parece clara ante todo, la mayor o menor cercanía a la línea de frontera no es un condicionante de la productividad, porque, por ejemplo, Galera, Orce y Cúllar están más cerca de ella que Freila, muy próxima a la

7 Archivo General de Simancas, Consejo Real, legajos 53 y 54. 
ciudad de Baza. Otra más es la correlación, que es del todo punto lógica, entre la capacidad productiva calculada y el número de vecinos contabilizados en el momento de anotar los datos. Así, Galera, que es la primera alquería de todas, cuenta con 200 vecinos; Orce, que le sigue, 100 vecinos, los mismos que Cúllar, que está después.

Todo ello, con las prevenciones que son aconsejables, nos permite afirmar que la vida fronteriza no era obstáculo para la productividad de unos términos, no ya desde una perspectiva ganadera, sino sencillamente agrícola. Las incursiones castellanas, que las hubo, no impidieron la puesta en valor de tierras de cultivo. Pero además hay que anotar que la capacidad productiva ganadera está en relación con la proximidad de la montaña (caso de Orce y Castril), aunque no sólo por eso. En Galera no hay pastos de verano próximos y, sin embargo, el ganado es notable. Seguramente, como en el resto de las alquerías y según una costumbre que ha perdurado hasta tiempos muy

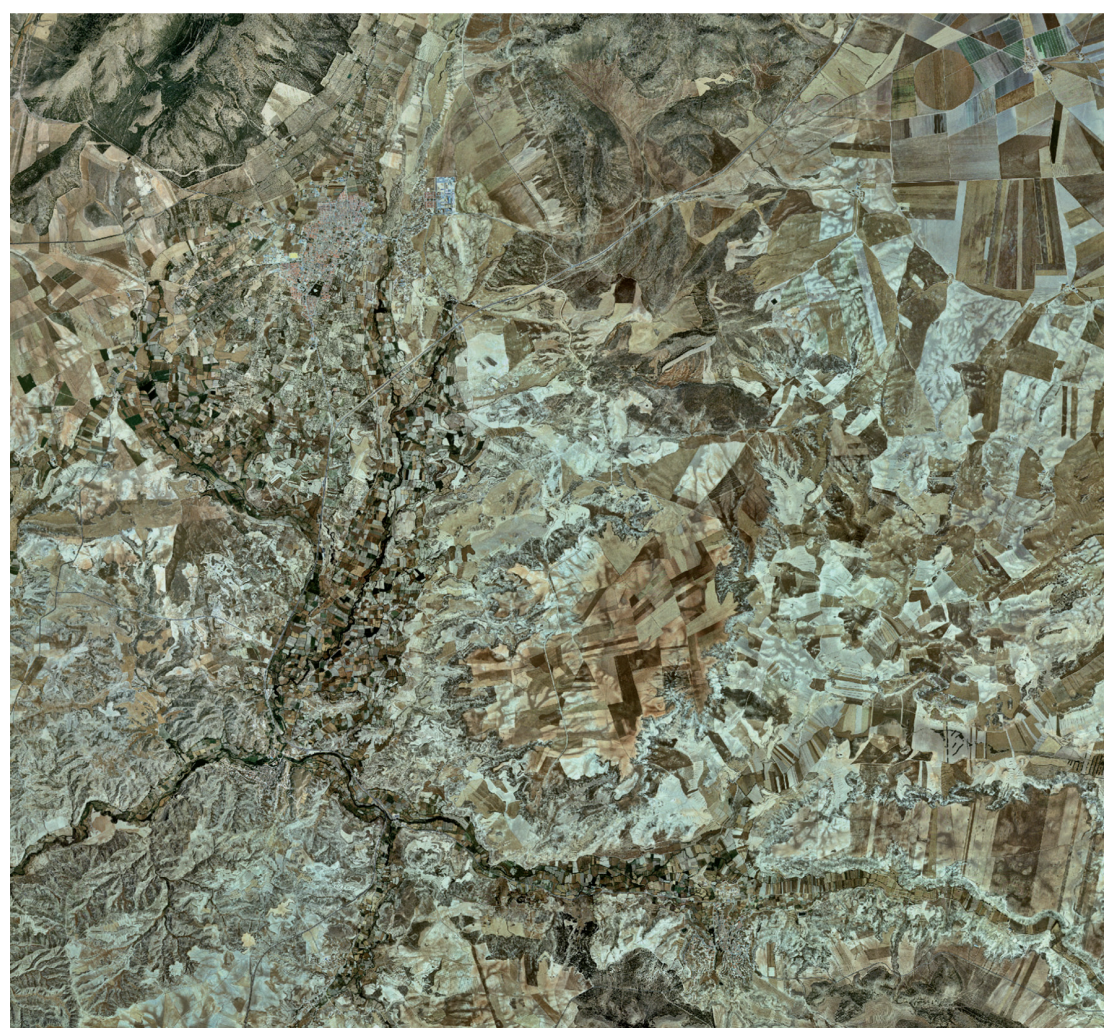

Figura 2. Área de cultivo irrigada en Huéscar, Galera y Orce, según el Mapa del Instituto Geográfico Nacional de España. 


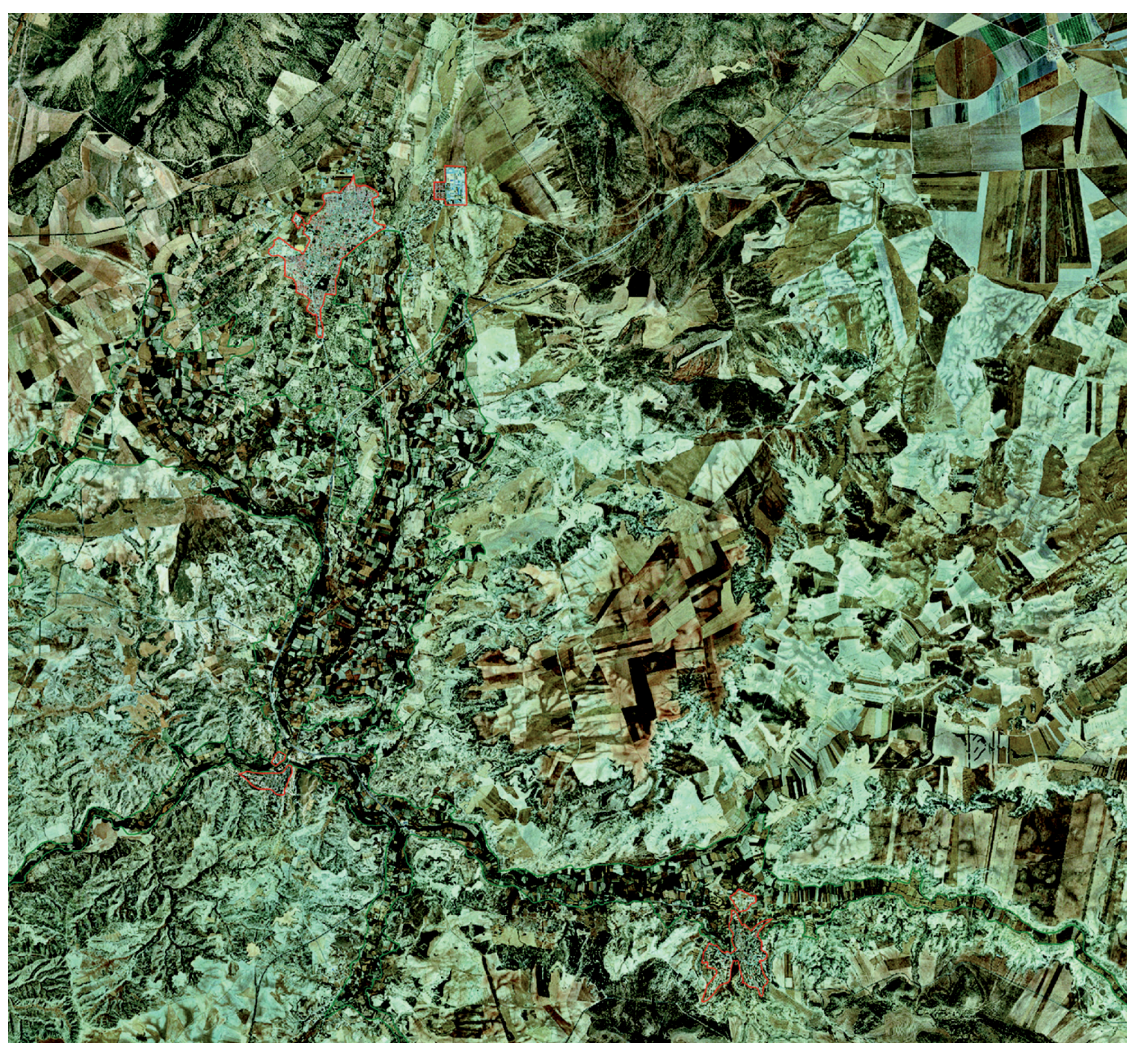

FIgURA 3. Áreas de cultivos irrigados en Orce en la misma cartografía.

recientes, los animales pastaban en el altiplano y en los meses de verano iban a las sierras más o menos cercanas. Es lo que sabemos por encuestas orales realizadas en el campo que nos han informado que marchaban a la Sagra, al norte de Huéscar, no muy distante de Galera. Tampoco estaba muy lejos la Sierra de Orce y, por tanto, la de María.

La vida agrícola, según se aprecia con cierta claridad, está muy relacionada con la presencia de agua. Siguiendo la cartografía más antigua es posible tener una imagen adecuada. He aquí, por ejemplo, los dos casos más significativos, el de Galera y Orce, que recogemos en dos imágenes diferentes.

Si tomamos la foto aérea de Castilléjar, como uno de los muchos casos que podríamos escoger, enseguida nos damos cuenta de lo que queremos decir. El agua ha configurado un espacio de cultivo irrigado en un medio estepario o casi desértico. El contraste es sencillamente espectacular, hasta el extremo de poder hablar de oasis que se hallan en un desierto. 


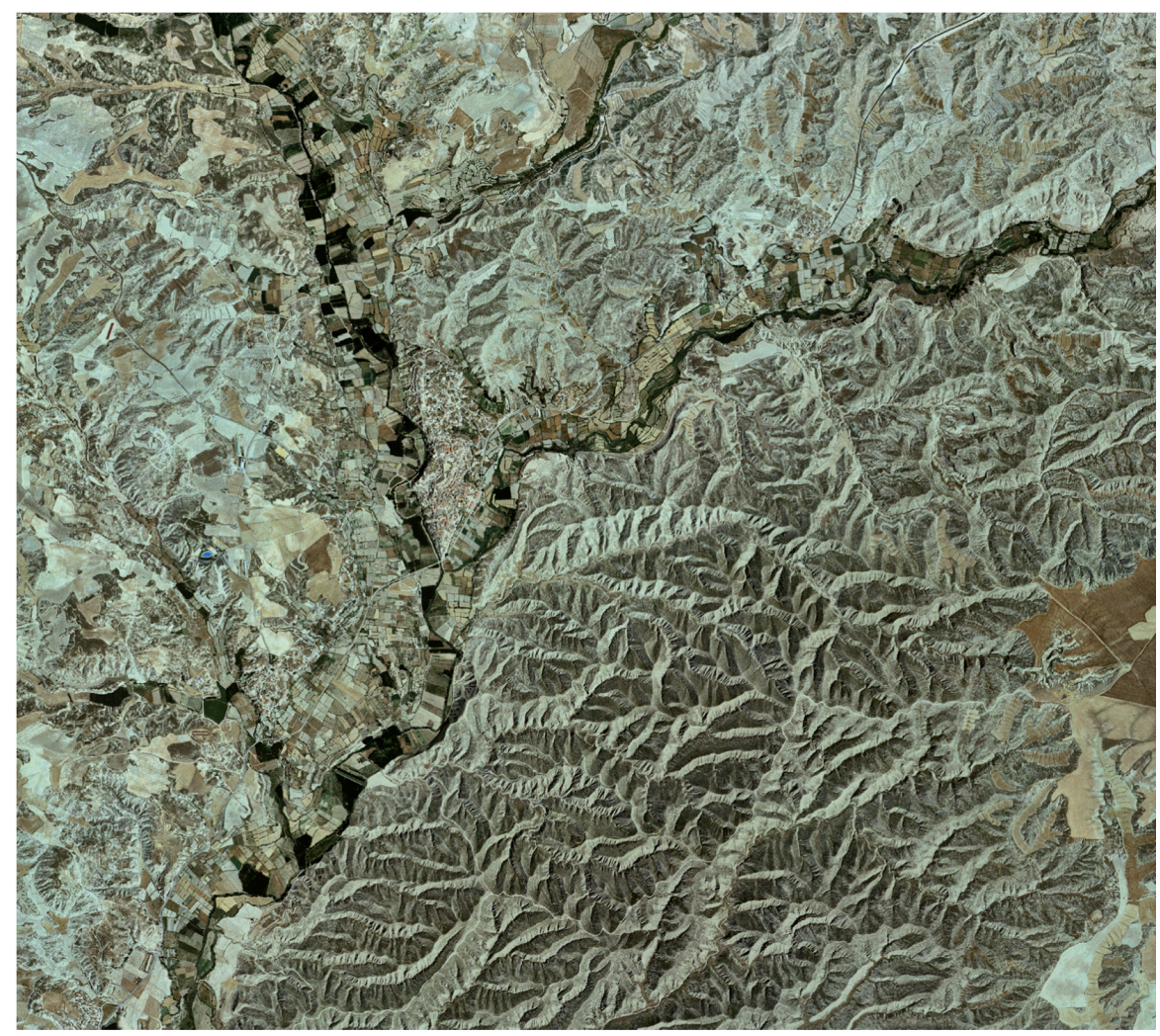

FiguRA 4. Área de cultivo irrigado en Castilléjar según la ortofoto de la Junta de Andalucía.

Acertadamente M. Bertrand y J. Sánchez han señalado la existencia de recursos hídricos que han permitido la creación de espacios dedicados a una agricultura intensiva. No basta con la presencia de agua, sino que hay que generar sistemas de irrigación ${ }^{8}$.

Teniendo en cuenta la disponibilidad de agua y su procedencia, hay que hablar de una diferencia entre las distintas áreas. Las más cercanas a Baza disponen de fuentes naturales de un caudal importante situadas en torno a los núcleos habitados (Baza, Caniles y Zújar). Otros cuentan con cursos más o menos permanentes, como los de los ríos Guardal, Guadiana Menor (este es el que recoge todas las aguas de la hoya bastetana) y Cúllar, que sirven

8 BERTRAND, Maryelle y SÁNCHEZ VICIANA, José R., «Canalizos y tajeas, dos sistemas de captación de agua mediante galerías subterráneas en las altiplanicies granadinas. Andalucía Oriental», Arqueología y territorio medieval, 16 (2009), pp. 151-178, especialmente pp. 151-152. 
para regar las tierras que se consideran más ricas del conjunto territorial. En la parte que hay al pie de las Sierras de Orce y Estancias no hay normalmente aguas superficiales, por lo que se ha acudido tradicionalmente a buscar las subterráneas por medio de galerías drenantes tipo qanãt/s. Probablemente muchas de ellas fueron construidas en tiempos contemporáneos. Esto último tiene una significación que no podemos ocultar. Ante todo pone de manifiesto la dificultad de establecer cronologías fiables en el estudio de los sistemas hidráulicos, pero también nos habla de la necesidad de considerar que la irrigación, una vez establecida, tiende a ser una opción que se desarrolla en cuanto es posible dada la riqueza agrícola que genera, máxime en un medio como este, semiárido, que limita la vida de los cultivos. A la larga se produce una sobreexplotación de un recurso tan valioso y, en el presente caso, tan escaso como el agua.

En época andalusí, era posible cultivar eventualmente espacios en los que había un poco de humedad como la que tenían cañadas y barrancos umbrosos. Al disponer de un uso limitado y eventual del agua, creemos que no eran cultivos permanentes, sino ocasionales.

Lo que ahora nos interesa resaltar son las áreas regadas de forma habitual y constante, o sea que necesitaban un aporte constante de agua. Las fuentes y los cursos de agua lo posibilitaban. Se debe sobre todo a la proximidad de montañas, algunas de las cuales permiten almacenar cantidades significativas en sus masas calizas.

La red hidráulica que se inicia en las montañas vecinas, procede del cuaternario y adopta una forma dendrítica en el altiplano. Todos los cursos de agua, que marchan desde direcciones distintas, confluyen en el Guadiana Menor, afluente del Guadalquivir, una vez que pasa por las montañas hasta llegar a la depresión bética.

La misma red fluvial ha creado vías de comunicación hacia el norte y ha ido fertilizando las tierras, hasta el extremo que se da un bello contraste entre los espacios que reciben el agua y aquellos otros que son esteparios. Esta es una característica en toda la hoya, quedando los núcleos actuales, que ya existían, como muy tarde, en época nazarí en medio de ese paisaje de vega $^{9}$. Semejan oasis en medio de un medio desértico y tal vez esa imagen sea la que reproducen, pues parece que el agroecosistema de regadío tiene su antecesor en el de oasis.

Todo este conjunto se abastece, como queda ya dicho, sobre todo de las aguas que descargan en forma de lluvias y de nieves en la orla montañosa que lo rodea.

9 MALPICA CUELLO, Antonio, «Paisaje y poblamiento...» 
La economía agrícola no se puede reducir, sin embargo a la agricultura irrigada, pues, para empezar, esta se halla estrechamente en relación con las sierras próximas, según queda reiteradamente dicho. Entre la montaña, de la que hablaremos luego, y las vegas hay un amplio espacio que no se puede despreciar en un análisis como el que venimos haciendo.

Las tierras semiáridas del altiplano tienen una cierta productividad, más de lo que pudiera parecer. No hay un único paisaje estepario, pues la vegetación nos da diferentes variantes. Se distinguen tres agrupaciones vegetales que la significan. Tenemos, en primer lugar, la estepa leñosa. Se caracteriza por predominar los arbustos leñosos y de pequeño porte. Son plantas halófilas y subarbustivas, sobre todo tarajes o taray (Tamarix gallica, L). Esta especie vegetal soporta una alta concentración salina y suelos margosos. Se agrupan en determinados puntos, quedando entre ellos frecuentemente calveros de suelo desnudo, con poca capacidad vegetal. No obstante, en primavera crece una vegetación primaveral, que es efímera, ya que está alimentada por las lluvias que caen en tal estación, que son escasas. Precisamente esas lluvias llegan a formar grandes cárcavas, formando un paisaje de badlands. En el fondo de esas barranqueras crece alguna vegetación que necesita mayor humedad, pero no entran propiamente en el medio estepario.

Otro conjunto estepario viene definido por plantas gramíneas altas, destacando las integradas por el albardín (Lygeum spartum, L) y el esparto (Stipa tenacísima, L). Tienen una aprovechamiento artesanal notable. A veces se encuentran algunos pies de árboles en ese tipo de estepa, pero son raros.

Por último, hay que hablar de la llamada estepa cerealística, que es obra humana. Tienen una consideración importante, ya que posibilitan un aprovechamiento ganadero con la comida por parte de los animales de las rastrojeras, práctica que se documenta en la época nazarí ${ }^{10}$ y que continúa aún. En ellas se da asimismo la posibilidad de caza de pequeñas aves y otros animales. Hemos de pensar que en principio esos espacios tienen un aprovechamiento agrícola mediocre, dado que la climatología condiciona mucho el crecimiento de los cereales. Es cierto que se encuentran especies adaptadas a la sequedad, al calor y al frío, pero no lo es menos que su productividad debe considerarse como complementaria de otras capacidades agrícolas de mayor importancia que ofrecen las vegas irrigadas. Teniendo en cuenta todo ello, se ha de anotar que se suelen aprovechar condiciones muy favorables, cuando llueve suficientemente y en caso de que haya una nevada que deja el campo con agua abundante. Entonces se siembra un cereal de corta duración.

10 Archivo General de Simancas, Consejo Real, legajo 53. 
Tema aparte es el de las cañadas que en este espacio territorial merece una atención especial. Apenas se ha estudiado, pero ha de ser considerado siquiera brevemente. Una cañada, como dice el DRAE, es un «espacio de tierra entre dos alturas poco distantes entre sí» ${ }^{11}$. De ese modo están protegidas de los vientos, del frío y del calor, y reciben un cierto aporte de humedad. En tal sentido, pueden ser cultivadas, asegurando un rendimiento suficiente para la inversión que requieren. No se trata propiamente de barrancos, ya que estos suelen ser más profundos y estrechos, por tanto poco utilizables. Su pendiente, por el contrario, es suave y, por tanto, accesible, con suelos formados por aluvionamientos, o sea, profundos. Tampoco son ramblas en el sentido en que se suelen denominar los grandes cursos que aparecen con agua violentamente y que tienen una mayor extensión y anchura.

Estas modestas cañadas no son en modo alguno despreciables, ya que permiten ser cultivadas, normalmente con cereales, y en ellas se alimenta el ganado, bien de las rastrojeras, bien de las hierbas que crecen cuando están sin labrar. Ofrecen, por tanto, una extensión de tierra, nada despreciable, para la economía campesina y el conjunto de la población.

Al ser cultivos en cierta medida ocasionales, no hay problemas de tipo legal, porque se trata por lo común de tierras que pueden ser explotadas sin problemas de propiedad. Su vivificación es un derecho que es inherente a aquellas que se consideran comunes y susceptibles de ser roturadas. Ese hecho de salir de fondos comunes y volver a él les confieren un carácter propio y ofrece una capacidad productiva que se ajusta a las necesidades. El hecho de que sean labradas no significa que, cuando no se plante cereal u otros vegetales, no tengan otra función, ya que el hecho de que se críen yerbas en ellas permite convertirlas en pastizales para el ganado. De hecho hay algunas extensiones que parece que cumplen tal función y que son objeto de cultivo y pasto para el ganado alternativamente o de una forma circunstancial en un caso $\mathrm{u}$ otro.

Muchas veces el empleo del término cañada es doble, porque sirve para esa agricultura en cierto modo ocasional y para el paso del ganado, dando a entender que tiene ese doble fin. En el entorno de Orce, por ejemplo, en tiempos nazaríes existían varias de esas cañadas, perdurando en la toponimia: Cañada de Cañepla y Cañada de Almaciles, ambas mencionadas en documentos castellanos posteriores a la conquista ${ }^{12}$. Su importancia viene aumentada por estar situadas en el tránsito del altiplano a la montaña, en el

11 Diccionario de la Lengua Española, vigésima segunda edición, Madrid, 2001, s.v. cañada.

12 Archivo General de Simancas, Consejo Real, legajo 53. 
camino que han de recorrer los hatos de ganado para subir a la montaña. A veces encontramos aljibes en sus proximidades o en las vías pecuarias, que sirven para que abreven en sus marchas.

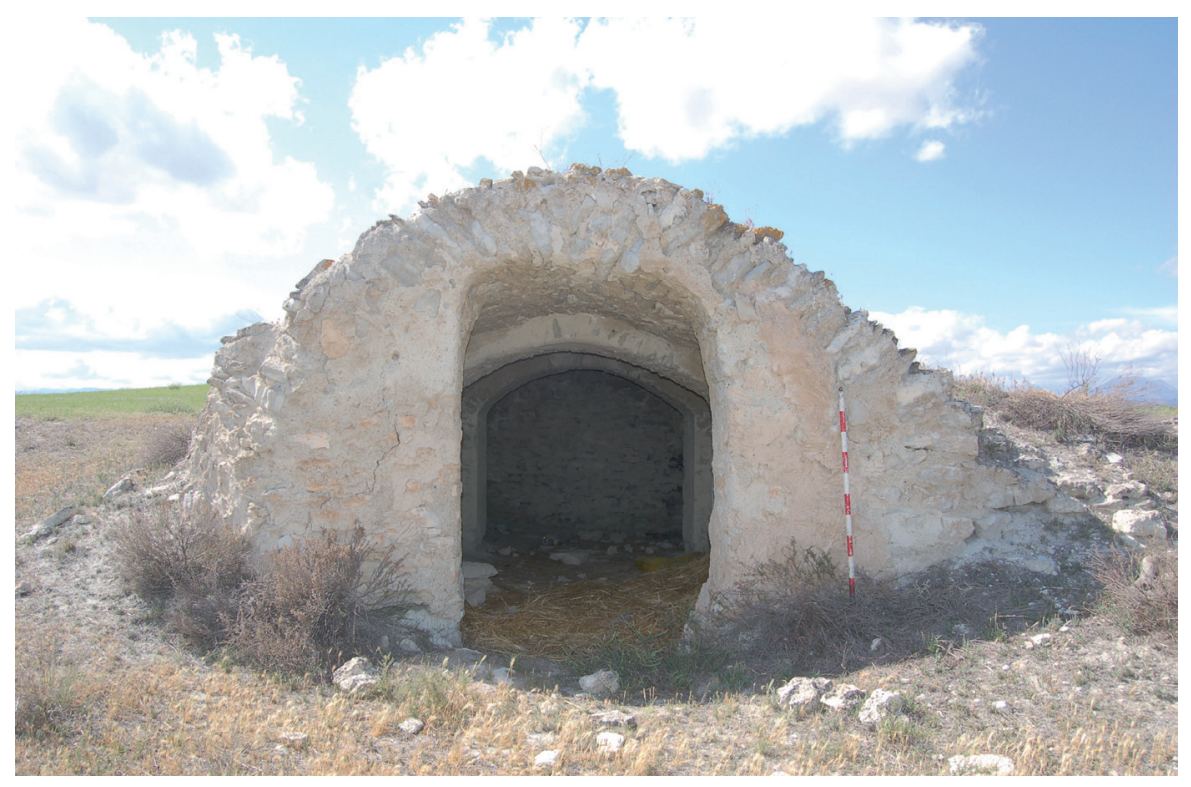

GRÁFICO 5. Aljibe en las proximidades de Galera y Orce en una ruta ganadera por el altiplano.

Es cierto que en el paisaje actual se detectan modificaciones en la organización del paisaje y sus adaptaciones y cambios. La infraestructura hidráulica que se percibe, por ejemplo, en la cañada que partiendo de Salar, en las proximidades de Orce, conduce a Venta Micena, lo pone de manifiesto. Como se aprecia en el gráfico 3, era un área de cultivo irrigado de cierta extensión, con una agricultura en mayor o menor medida intensiva, pero actualmente se ha reducido el espacio dedicado a los cultivos y tiene un mayor aprovechamiento ganadero, quizás por la despoblación de la zona. Así hay muchos pozos y abrevaderos para los animales. No suelen ser muy espectaculares pero ponen de manifiesto lo que hemos señalado.

Otra cuestión que merece la pena tenerla en cuenta es que la torre atalaya situada en los inicios de la cañada desde Orce a Venta Micena, llamada del Salar no solo sirve para vigilar el movimiento de los posibles enemigos que se internaran en el altiplano, sino también para controlar el paso del ganado, seguramente para protegerlo, pero también para poderlo cargar fiscalmente con el impuesto del talbix. 


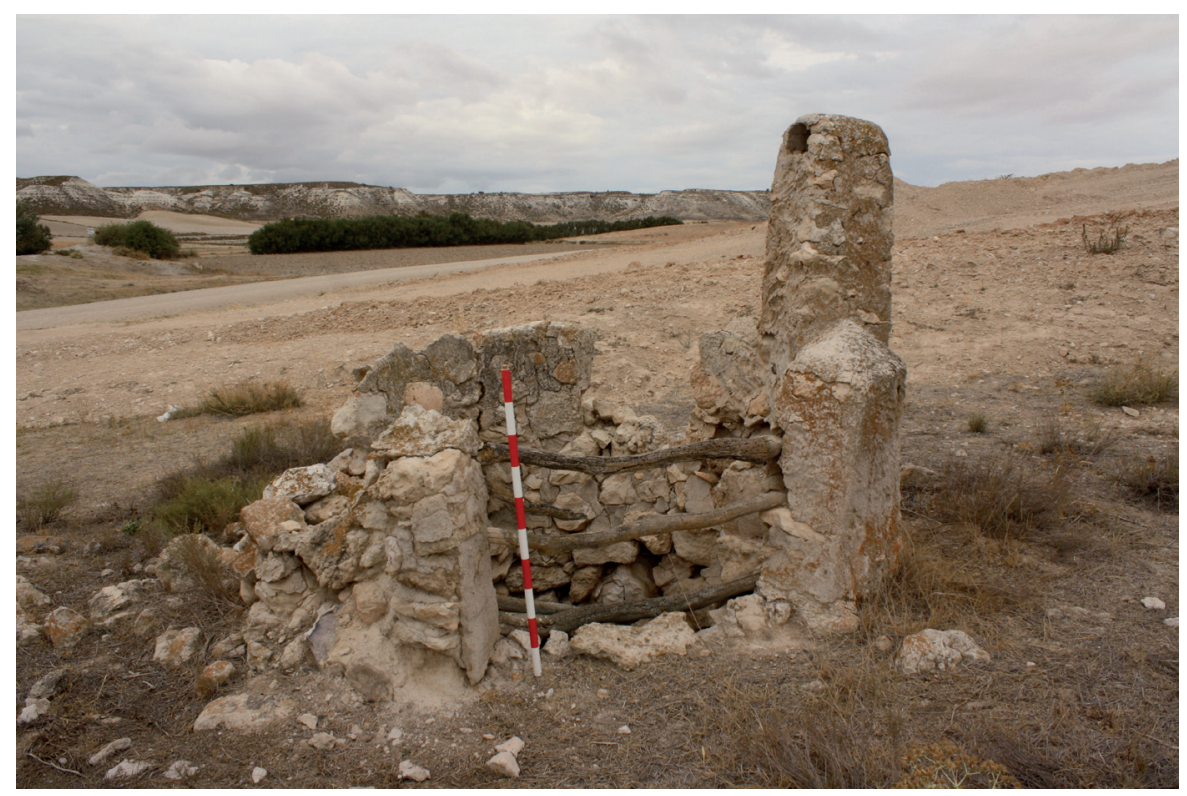

Gráfico 6. Pozos y abrevaderos en la cañada de Salar.

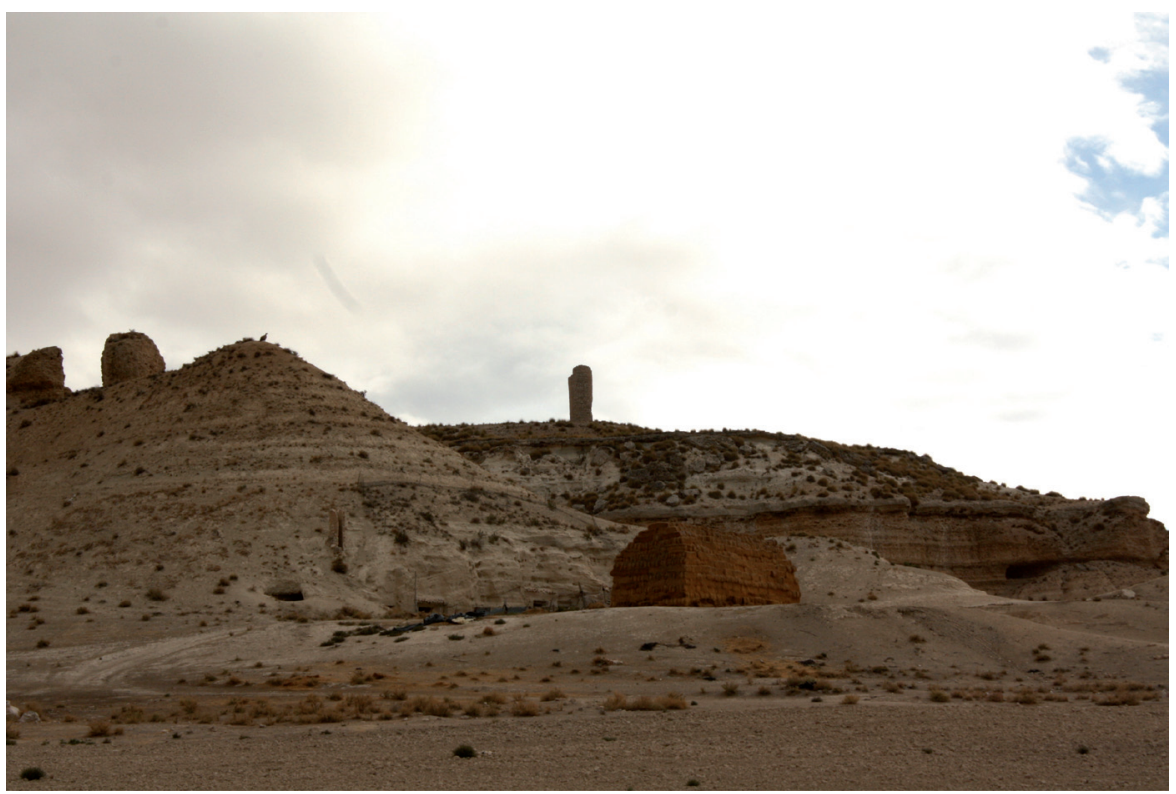

Gráfico 7. Torre del Salar sobre la cañada de ese nombre. 
El talbix era una carga que pagaban los ganados foráneos que entraban en términos que no eran los suyos ${ }^{13}$. Plantea un problema de entrada. Sabemos que los ganados podían pastar libremente al ser los pastos comunes en todo el reino de Granada. Ahora bien no es menos cierto que existían unas tierras que se reservaba cada alquería para su aprovechamiento directo comos pastizales. Son las que se denominan harim, reservadas y protegidas. Eran controladas directamente por la comunidad de cada lugar. Las otras eran colectivas y las cuidaba el Estado en cuanto representante de la umma. Eso supone una confusión, ya que el talbix debía corresponder a esas últimas, toda vez que lo cobraba cada alcaide, que era representante del rey nazarí y no el alguacil en nombre del concejo de ancianos de cada alquería. Y, sin embargo, las tierras estaban reservadas para cada una de ellas ${ }^{14}$. Esta cuestión es hasta cierto punto normal, ya que la penetración del Estado era una realidad en el mundo rural nazarí, aprovechando la confusión entre umma y poder estatal.

A veces las cañadas son denominadas «hoyas» ${ }^{15}$, término menos usado, pero que parece que se trata de espacios menos extensos rodeados también de elevaciones. Así, aparece una "Hoya del Muerto», como se recoge en los testimonios de diferentes testigos en un pleito que se llevó a cabo entre Orce y los Vélez. Sólo hemos recogido, como ejemplo, la declaración de uno de ellos, Abrahem Albolote, vecino de Huéscar, aunque hay muchos otros que se expresan en términos similares. He aquí lo que declara:

mas que oyo dezir a Muça ben Muça, difunto, su tyo, como los vecinos de la dicha villa [de Orce] senbrauan en la Hoya del Muerto, que es en el dicho termino de la diferençia çerca del limite» ${ }^{16}$.

Por tanto, nada de espacios baldíos, sino un aprovechamiento de cuantas posibilidades había, con una dedicación desigual, según la capacidad productiva de cada tierra y la inversión que era precisa para su aprovechamiento y/o puesta en valor.

13 Un primer trabajo es el de GALÁN SÁNCHEZ, Ángel, «Acerca del régimen tributario nazarí: el impuesto del talbix», en Hacienda y comercio. Actas del II coloquio de Historia Medieval Andaluza, Sevilla, 1982, pp. 379-392.

14 Estas cuestiones y otras, con especial referencia al talbix, las hemos recogido en nuestro trabajo: MALPICA CUELLO, Antonio, «Organización del territorio y estructuras económicas en la frontera nororiental del reino de Granada», en VILLAR MAÑAS, Sonia (ed.), Sal, agricultura y ganadería: la formación de los paisajes rurales en la Edad Media (en prensa).

15 Puede referirse a una extensión grande («Llano extenso rodeado de montañas»), o a otra más reducida ( Concavidad u hondura grande formada en la tierra»). Sobre sus significados, vid. Diccionario de la Lengua Española, vigésima segunda edición, Madrid, 2001, s.v. hoya.

16 Archivo General de Simancas, Consejo Real, legajo 53, fol. I. 
Además, hay que hablar de los espacios de criptohumedales, que en tiempos recientes están volviendo a tener una consideración mayor y se busca su recuperación, pues durante un largo período han sido desecados.

El mejor conocido es el de El Margen, en el término de Cúllar. La ficha elaborada por la Consejería de Medio Ambiente de la Junta de Andalucía, nos ofrece alguna información de interés. En cuanto a la hidrología nos dice:

Este criptohumedal constituye una depresión extensa y semiendorreica que de forma natural drena hacia una red hidrológica más amplia, aunque la escasa inclinación del terreno dificulta el drenaje y permite que el agua de escorrentía circule lentamente a través de ella y se acumule e infiltre en los materiales acumulados. Los procesos erosivos de las laderas son intensos y acumulan en la depresión una gran cantidad de material aluvial compuesto por arcillas, limos y gravas, que en algunos casos pueden tener un gran espesor. La acción antrópica en estos valles para su explotación agrícola ha conducido a incrementar su capacidad de drenaje, construyendo un sistema de canales y drenes que evacuan el agua superficial y subterránea ${ }^{17}$.

Este criptohumedal permanece con agua en invierno y primavera, secándose en verano y permaneciendo así hasta que las lluvias otoñales lo recargan. A veces, la acción humana ha contribuido a su casi desaparición, como se aprecia en el caso del llamado «El Baíco», en las cercanía de Baza, en dirección a Benamaurel. La existencia de canales de desagüe lo han puesto en peligro de desaparición, aunque sigue en la actualidad vivo ${ }^{18}$.

No se trata de humedales propiamente dichos, sino humedales de tránsito en los que estacionalmente se produce una descarga de agua, pero que, cuando se evapora, afloran sales (cloruros y sulfatos) a consecuencia de la disolución de los yesos triásicos de la cuenca. Se puede decir que son saladares.

Hay varios, algunos que no son fáciles de identificar en la Hoya de Baza. Además de la función de humedal cuando tienen agua, que permite que haya aves y, por tanto, con un aprovechamiento para la caza, hoy prohibida, sirven para alimento del ganado en verano. Las costras de sal pueden ser ingeridas en ciertos casos, porque no siempre se trata de $\mathrm{Cl} \mathrm{Na}$, sino también de $\mathrm{Cl}$ $\mathrm{Mg}$, que no es tan favorable para los animales. La vegetación halófita que allí crece puede ser alimento de los ganados.

En suma, estos espacios tienen una función primordial en la organización económica del territorio. No sustituyen a las salinas, que se concentran en

17 http://www.juntadeandalucia.es/medioambiente/web/Bloques_Tematicos/Patrimonio_ Natural._Uso_Y_Gestion/Espacios_Protegidos/humedales/inventario_humedales_provincias/granada/saladar_del_margen_ficha.pdf

18 Sobre este criptohumedal, vid. MARTÍNEZ MARTÍN, Francisco, «Aproximación a los saladares granadinos: el criptohumedal de Molino Baíco (Baza, Granada)», Péndulo. Papeles de Bastetania, 11 (2010), pp. 9-24. 
determinados puntos, pero palian la necesidad de sal de los rumiantes.

En realidad las explotaciones salineras se hallan fuera de esta área del altiplano. Las hay en el piedemonte de la Sierra de Quesada y, una vez pasada esta hacia el norte, ya en el Alto Guadalquivir ${ }^{19}$. En el área serrana de Murcia también encontramos alguna, como las de El Salero. Propiamente hay sólo una explotación la llamada de Bácor, en el cortijo de los Barcheles, que aparecen en la documentación del concejo bastetano ${ }^{20}$ y que aparecen como pertenecientes al conde de Tendilla en su testamento ${ }^{21}$.

Tenemos, sin embargo, la duda de que estas salinas fueran el único aprovisionamiento de sal. Es posible que se consiguiera en otros puntos, como los ya mencionados saladares, al menos para las necesidades inmediatas. El rígido control de la producción salinera, que está muy claramente documentado en tiempos posteriores a la conquista, pero que hay indicios suficientes para pensar que antes de ella, en el período nazarí, se ejerciese una vigilancia sobre la producción y venta de sal, se explica por la fiscalidad existente. Es evidente que había mecanismos para escapar de ese rigor. Además, hay condiciones físicas para obtener sal en el altiplano, aunque siempre hay que pensar en pequeñas explotaciones que escaparían a la fiscalidad estatal.

Las características edafológicas del altiplano han condicionado su utilización y aprovechamiento. Los suelos de este son por lo general margas y yesos, que determinan que el espacio cultivado no fuese muy productivo, salvo en las tierras de aluvión de los valles y en las cañadas en menor medida.

La montaña, que es el tercer elemento del que cabe hablar, no es demasiado elevada, pero suficiente para permitir albergar cabezas de ganado durante el verano en sus pastizales. Hay diferentes puntos en los que se llega a superar los $2000 \mathrm{~m}$. Son varias las sierras que rodean el altiplano y que se relacionan con él.

En general alcanzan en sus cumbres más elevadas los 2000 m y aún más. En la Sagra, al norte del conjunto, su punto más elevado llega a los $2138 \mathrm{~m}$; en la Sierra de Castril, que es una prolongación de la de Cazorla, y que se halla también al noreste, se superan los 2000 m en diferentes puntos. Así,

19 QUESADA, Tomás, «Las salinas de interior de Andalucía oriental: ensayo de tipología», II Coloquio de Historia y medio físico. Agricultura y regadío en al-Andalus, (Almería, 1995), Granada, 1996, pp. 317-333, y QUESADA QUESADA, Tomás y MALPICA CUELLO, Antonio, «Las salinas de Andalucía Oriental en época medieval. Planteamientos generales y perspectivas de investigación». Journal of Salt-History, 2 (1994), pp. 144-169.

20 ANDÚJAR QUESADA, Ana, El concejo de Baza según las Actas capitulares de 1508, Granada, 1987, Memoria de licenciatura inédita, p. 90.

21 MENESES GARCÍA, Emilio, Correspondencia del Conde de Tendilla, I (1508-1509), Madrid, 1973, p. 82. 
su mayor altitud está en Empanadas, con 2107 m. Más al este, en la Sierra Seca está Tornajuelos, que llega a 2138 m. En la Sierra de Baza, al sur, se superan en varios puntos los 2200 m (Calar de Santa Bárbara, 2269 m, que es la máxima altitud; Relumbres, 2268 m; Calar de Rapa, 2264 m), destacando la existencia de los llamados Prados del Rey, a 2202 m, que son unos prados húmedos destinados a pastos de verano para el ganado. En las montañas orientales, la Sierra de Orce y de María, hay que reseñar las altitudes de María (2045 m), Cabezo (1948 m), Maimón (1754 m), que esta casi encima de Vélez-Rubio y la Muela de Montalviche (1554 m). Son alturas que desciende hacia el este; en la Sierra del Gigante, con una orientación SO-NE, son menores: Gigante (1493 m), y en la parte meridional de esa sierra, que sirve de límite, hallamos Colmillo (1158 m) y Cunica (1148 m).

Está bien documentado el paso de hatos del altiplano a esas sierras, que en determinadas áreas ofrecen pastizales con hierbas y aguas abundantes. A los citados Prados del Rey, en la Sierra de Baza, hay que añadir otros puntos en esa montaña, perdurando hasta tiempos actuales. El hecho de que aquel espacio, prado húmedo, como queda dicho, se denomine de esa manera, que también se emplea en otras zonas del reino de Granada, como en las proximidades de Huétor-Santillán, nos hace pensar que se trataría de un área protegida y preservada. En un primer momento sería de una comunidad concreta, la que la solía utilizar, que la reservaba para un uso sostenible, impidiendo el sobrepastoreo que alteraba las posibilidades y alteraba el sistema ecológico. Es lo que existe en el Atlas norteafricano, que suele denominarse «agdal» ${ }^{22}$.

De esa cuestión hay otros ejemplos, como los que recogió C. Trillo, aunque el problema a veces no ha sido claramente planteado ${ }^{23}$. En el primero

22 Sobre este tema, entre otros trabajos: DOMÍNGUEZ, Pablo, «Transformación de instituciones religiosas tradicionales en el Alto Atlas de Marrakech (Marruecos) y su impacto en los ecosistemas subalpinos. Caso del sistema pastoral del agdal», Perifèria. Revista de recerca i formació en antropologia, número 7 (diciembre 2007), pp.1-26. En formato digital: http://antropologia.uab.es/Periferia/ Articles/ecologia_yagur_pdominguez.pdf; DOMINGUEZ, Pablo, ZORONDO RODRÍGUEZ, Francisco y REYES GARCÍA, Victoria, «Relationships between religious beliefs and mountain pasture uses: A case study in the High Atlas mountains of Marrakech, Morocco», Human Ecology, 38, (2010), pp. 351-362; DOMINGUEZ, Pablo, BOURBOUZE, Alain, DEMAY, GENIN, Sébastien, y KOSOY, Nicolas, «Diverse ecological, economic and socio-cultural values of a traditional common natural resource management system in the Moroccan High Atlas: the Ait Ikiss Tagdalts», Environmental Values, 21 (2012), pp. 1-20.

23 TRILLO SAN JOSÉ, Carmen, «Un señor castellano y un alfaquí converso. La difícil convivencia después de la conquista del reino de Granada», Revista Marroquí de Estudios Hispánicos, Universidad de Fez, III (1992), pp. 51-66»; «El paisaje vegetal en la Granada islámica y sus transformaciones tras la conquista castellana», Histoira agraria, 17 (1999), pp. 131-152, y «La organización del espacio de la alquería en la 
de los que publicó se refiere a la demanda de un alfaquí de la Alpujarra, que decía que los pastos eran de su propiedad ${ }^{24}$. No parece que se trate de un pastizal administrado por el Estado, sino tal vez por la comunidad de aquel término. Eso no quiere decir que no pudiera ser una «agdal» controlado por el grupo campesino, pero tampoco que entrase dentro de las tierras harim y por eso estuviesen defendidas. Es una cuestión a estudiar con mayor profundidad.

En otro ejemplo se menciona la reserva de pastos en la Sierra de la Sagra por parte de D. Luis de Beaumont, condestable de Navarra, que suele arrendarlos en contra de los propios vecinos de Huéscar ${ }^{25}$. Es esencial en este caso dilucidar si se tratan de pastizales reservados y «apropiados» («agdal») por el poder estatal o libres. Estos últimos se suelen denominar «tishka» ${ }^{26}$. Ambos términos son de la zona del Atlas marroquí, pero al menos el segundo ha dejado huella toponímica en la zona norte del distrito, que cayó en manos castellanas en torno a mediados del siglo $\mathrm{XIV}^{27}$, y sobre cuya dedicación ganadera no hay duda, como señala, por ejemplo, Idrisi en el siglo $\mathrm{XII}^{28}$.

El trabajo de campo que venimos desarrollando en los últimos tiempos revela la continuidad en la explotación ganadera de pastos a partir de los 1500 m hasta los 2000 en algunos casos. Así, en la Sierra de Castril, en el Peñón del Toro, por encima de los Prados del Conde, la altitud llega de 1800 $\mathrm{m}$ a $2000 \mathrm{~m}$, en tanto que estos últimos alcanzan los $1700 \mathrm{~m}$.

En realidad, en esa área la práctica ganadera existía en tiempos nazaríes. Sin duda, las sierras de todo el conjunto acogían ganado propio, pero también de fuera, como hemos señalado en otros trabajos anteriores ${ }^{29}$.

frontera nororiental del reino de Granada», Studia historica, Historia Medieval, 24 (2006), pp. 227-240, donde usa el mismo dato.

24 TRILLO SAN JOSÉ, Carmen, «Un señor castellano...»

25 Archivo General de Simancas, Consejo Real, leg, 59, fol 7.

26 «...le tichka c'est l'alpage en vaine pâture alors que l'agdal est une pâturage réservé par des accords et de pactes pastoraux en période tribale (ou par appropiations privé ultérieurement). Sur les Agdal on retarde la montée au pâturage parfois jusqu'au début d'août, pour permettre croissance végétative. Cette montée est l'occasion des festivités et de cultes syncrètiques rappelant fortement les scènes gravées sur les plateaux de Yagour et de l'Oukaïmeden il y a 4.000 ans» (PASCON, Paul, Le Haouz de Marrakech, 1977 , t. I, p. 164, nota 15).

27 Gran Crónica de Alfonso XI, edición de CATALÁN, Diego, Madrid, 1976, vol. I, capítulo XX, p. 313.

28 «en la cima de esta montaña hay rebaños y campos cultivados y perfectamente irrigados» (IDRISI, Description de l'Afrique et de l'Espagne, edición del texto árabe y traducción francesa de Dozy, Reinhart, P. A. y De Goeje, Michaël J., Leiden, 1866 (reimpresión Amsterdam, 1966), p. 202 texto árabe; p. 248 traducción).

29 En concreto sobre esta área: MALPICA CUELLO, Antonio, «La vida económica en la frontera nazarí-castellana. Ganadería y sal en la zona nororiental del reino de 
La montaña tenía una penetración ganadera, pero a menor altura es posible que hubiese espacios agrícolas, tipo «michar», que en algunos casos estarían irrigados.

Los pastos requieren una atención especial, ya que no deben de soportar una carga excesiva. El ganado contribuye a un equilibrio, pues se mantiene a un determinado nivel de extensión y altura. Suelen ser plantas adaptadas a un clima extremo, en el que el frío es intenso en invierno, con agua muy abundante en la época del deshielo. Si se alteran es difícil la recuperación y se produce una destrucción del ecosistema. Es cierto que los ganados abonan los suelos de los pastizales, pero si hay un sobrepastoreo no sólo inciden en el crecimiento de las hierbas y nitrogenan en exceso, haciendo que crezcan plantas no forrajeras de las que los animales no se alimentan.

El espacio más bajo, entre la montaña y los asentamientos del altiplano sirven de punto de relación entre ambas realidades físicas. Pueden darse en él pequeñas explotaciones que marcan la transición de una ocupación agrícola a otra exclusivamente ganadera, sirviendo de escalón para los ganados que suben a finales de la primavera a las sierras y que bajan ya en otoño a la llanura. Es posible que algunos de ellos, como el situado en el área en donde hoy está situada la ermita de Las Santas, entre Huéscar y La Puebla de Don Fadrique, en la Sagra, tuvieran un carácter sacralizado, siendo un punto de encuentro sin más problemas de cuantas personas y animales iban o venían, según la época del año, a las cumbres montañosas.

Es cierto que en algunas áreas esa transición viene dada desde el mismo altiplano, con la presencia de campos de cultivo, por lo común de cereal, y aljibes ganaderos de evidente importancia dada su capacidad, reflejada en el volumen de agua que pueden almacenar. Están situados en cañadas que permitían el paso de los animales a los pastos de verano. Lo vemos, por ejemplo, en el llamado Campo de María. Allí hay tierras de secano, en las que el cereal es dominante, con alternancia de hojas de cultivo. En el escalón ya próximo a la Sierra de María, en la parte oeste de ella, encontramos varios aljibes indudablemente ganaderos, aunque se utilizaran en tiempos más recientes como

Granada», en LITCHFIELD, Carol D., PALME, Rudolf y PIASECKI, Peter (eds.): Le monde du sel. Mélanges offerts à Jean Claude Hocquet. Journal of Saltt-History, 8-9 (2000-2001), pp. 101-124, y, en todo el conjunto fronterizo: «Agriculture, Livestock and Salt in the Kingdom of Granada. A study of the economy and territory of the Nazari Zone», en INGENHAEFF, Wolfgang, STAUDINGER, Roland y EBERT, Kurt (eds.), Festschrift Rudolf Palme, Innsbruck, 2002, pp. 337-352, y «Las salinas en la frontera del reino nazarí de Granada y su papel en la economía ganadera castellana», en Thesis. Wissenschaftliche Zietschrift der Bauhaus-Universität Weimar, 48, 4/5(2002), pp. 236-246. 
punto de abastecimiento de los cortijos allí existentes. Uno de ellos, el de los Falces, tiene una capacidad algo superior a los 700000 litros. La encuesta de campo que hemos realizado ha puesto de manifiesto como algunas personas insistían en que se llenaba con una acequia procedente de una fuente en el mismo pie de la montaña. Se trata de la Alfahuara, que riega a su vez una pequeña área de cultivo, similar a un michar, y que marcaría una vez más lo ya dicho sobre la transición entre el llano y la montaña, el paso de la vida agraria a la exclusivamente ganadera.

\section{LOS ASENTAMIENTOS DEL DISTRITO BASTETANO}

En definitiva, el territorio que rige la ciudad de Baza integra actividades económicas que no se interfieren, de la agricultura intensiva irrigada a la vida ganadera en la montaña. Eso determina que la capacidad productiva del distrito esté conformado por líneas diferentes, en algunos casos complementarias (agricultura de secano y ganadería en el altiplano), pero en otros no asimilables. De ese modo, la población nazarí se dedicaba a diferentes formas de producción, pero todo indica que la principal era la vida agrícola intensiva que permitía la irrigación, aunque no desdeñaba otras fuentes, algunas notables, de riqueza. La ubicación de los núcleos habitados confirman ese papel primordial de la agricultura irrigada, porque están todos ellos asociados a vegas cultivadas gracias al suministro constante de agua.

Los asentamientos humanos principales, como ya se ha dicho están en el área baja. En su mayor parte se sitúan en los ríos que conforman la red hídrica del altiplano. Hay que añadir que, además, son las vías de penetración al mismo corazón del distrito, Baza, y, por tanto, destacan también por la capacidad defensiva, que no sólo cabe entenderla en cada caso particular, sino con respecto a todo el conjunto territorial. De ese modo, la ciudad que lo rige se halla protegida por una serie de estructuras ocupadas y fortificadas.

La primera línea defensiva está formada por Castril y Huéscar. Cerca del primero hay, además, pequeños asentamientos agrícolas que se benefician de sendas fuentes para regar sus tierras, Lezar y Cebas. El mismo Castril se aprovecha de la fuente de Tubos, con su área de cultivo a los pies mismos de su fortificación. Es un recinto amurallado con dos partes bien diferenciadas: la superior, o espacio del poder, en la que se situaron los castellanos, y la inferior, en donde estaba la población, que desbordaba las murallas. Su cementerio estaba en el camino hacia Huéscar, a un lado de la acequia, fuera del recinto defensivo. Castril ocupa el punto en el que el río del mismo nombre se abre al salir del dominio montañoso que tiene a sus espaldas y se hace un 
curso del altiplano, que va en dirección sur. Huéscar, que hoy en día es casi capital de la pequeña comarca situada al norte de Baza, está en un llano, en el piedemonte de unión entre la montaña y el altiplano. Una serie de mecanismos defensivos la protegían a ella y al espacio que permitía el paso hacia el sur. Nos referimos a las fortificaciones de Mirabetes, Volteirola y Huéscar la Vieja, que sin duda estaban ocupadas en el siglo XIII y que probablemente se siguieran utilizando a lo largo del período nazarí. Seguramente albergaban a pequeñas poblaciones y a unas guarniciones que las protegían. Pero al no haber sido excavadas y sólo contar con análisis genéricos es poco más lo que podemos añadir. Lo cierto es que Huéscar era un punto crítico, por lo que estaba amurallada, toda vez que permitía, una vez en ella, el paso hacia el sur, estando casi en la misma raya de la frontera. Su proximidad a la Sierra de la Sagra permitía una actividad económica ganadera muy notable, como lo prueba el uso de los pastos de verano de ella, que aún es perceptible. Es más, esta sierra recogía ganados de ambos lados, el castellano del norte y el nazarí de gran parte del distrito.

Si descendemos hacia el sur hallamos un arco defensivo que controla los pasos que abren los mismos ríos. En primer lugar Galera, que se halla en el punto de encuentro del curso de agua que baja de Huéscar y el que viene por el este de Orce. Con una estructura defensiva que se documenta en la guerra de la rebelión de los moriscos, pero que hoy ha desaparecido, era un núcleo muy poblado, el mayor del todo el distrito, al menos en la documentación que ya hemos citado. Cerca de él encontramos hábitats menores, como el Marchal, un cortijo, que continúa con su nombre, pues tal vez fuera un michar en tiempos nazaríes, y el espacio llamado la Alquería, en la que la dedicación ganadera con prados irrigados no interfiere el área agrícola propiamente dicha. En este último caso no podemos precisar si tenía tales características antes o bien fue transformado para conseguir alimentar a un ganado de cierta entidad que aumentaría sin duda en tiempos posteriores a la conquista. En todo caso el amplio espacio del altiplano que hay de Galera a Castilléjar, al suroeste, y de aquella a Orce, al sureste, se empleó como tierras en el que el ganado pastaba y que recorría de oeste a este para subir en verano a la Sierra María. También ese movimiento se daba hacia la montaña de la Sagra.

Orce ocupaba el principio, o final, según se vaya o venga, del camino hacia la montaña situada al este, Sierra María. Su núcleo estaba protegido por una fortaleza modificada en tiempos castellanos por los Enríquez, que la recibieron como señorío. En su término había dos espacios de cultivo diferenciados, el que se halla entre Venta Micena y ocupa la cañada de Salar, esta última al oeste, y el propiamente de Orce con Fuencaliente al oeste. Hay otras 
cañadas y hoyas en su entorno que le sirven para disfrutar de una agricultura irrigada o de secano, que parecería imposible en un medio tan seco y con un componente edafológico que genera suelos tan pobres, fundamentalmente margas y yesos. Era el punto que controlaba asimismo el paso a los pastos de verano de Sierra María. Todo ello explica la presencia de atalayas (la de la Umbría y la de Salar), precisamente en esa vía, lo que nos hace pensar que, además de tener como misión vigilar ese camino, servían para controlar el paso del ganado, puede incluso que con fines fiscales. Esta vía está llena de pozos y abrevaderos, y, al llegar al ya mencionado Campo de María, de aljibes, que estaban para satisfacer las necesidades del ganado y de los pastores.

Castilléjar, al suroeste de Galera, como se ha dicho, cubría la comunicación hacia el sur y controlaba la vía del río Guardal. Con una vega en el fondo del valle, tiene también algunos puntos irrigados en sus términos que no se han estudiado aún, pero que incluso pudieran ser anteriores a la gran expansión agrícola del siglo XVIII. La cría de ganado en el altiplano, que en la actualidad es un hecho comprobado, existiría en tiempos nazaríes, en relación con las otras alquerías. Todo indica además que tuvo una estructura defensiva, de la que hoy no queda nada más que el recuerdo.

Al sur de Castilléjar, tanto hacia una parte como otra, hay otros asentamientos que conformaban el segundo anillo de protección. Siguiendo el curso del Castril se halla Cortes, también con una pequeña estructura amurallada bárbaramente destruida no hace tantos años. Cuenta con una vega regada por el Castril y el fondo del valle que forma este.

Hacia el este y un poco más hacia el sur, en torno al río Guardal está Benzalema, que parece que tuvo mecanismos defensivos. Su vega se beneficia del río, cuyas aguas fertilizan las tierras situadas por debajo del núcleo habitado.

Más al sur aún, pero también hacia el este, cubriendo el paso de los Vélez, está Cúllar. Con una estructura defensiva, de la que sólo nos queda una torre incorporada a una ermita actual, por debajo el río, que pasa por los pies de la elevación en donde está la fortificación, permite regar una vega de cierta extensión. Es probable que el núcleo estuviese antes en esa elevación y que fuera bajando a la zona llana, como sabemos que ocurrió en otros territorios no muy lejanos y relacionados con la misma Baza, en concreto en el valle del Almanzora. Lo cierto es que la estructura que subsiste, la gran torre aneja a la ermita, es una obra nazarí, hecha en mampostería con líneas de lajas de piedras, pero sobre un tapial calicastrado que debió ser anterior. En el siglo XII ya existía, como nos muestra la crónica almohade Al-man bi-l Imama ${ }^{30}$.

30 IBN SAHIB AL-SALÃ, Al-mann bi-l-imama, traducción de HUICI MIRANDA, Ambrosio, Valencia, 1969 , p. 81. 
La importancia de Cúllar es indudable, porque si se llega a ella desde la frontera oriental, se puede desembocar fácilmente en Baza o subir hacia el norte al corazón del altiplano. No lejos de Cúllar, hacia el oeste, encontramos el criptohumedal del Margen, topónimo que significa «pasto». Es un punto de alimento y provisión de sal para el ganado. Más hacia el oeste se llega a la ya mencionada Benamaurel.

Más hacia el oeste, en el tramo en el que se unen el río Castril y el Guardal, se ubicaba Benzalema, despoblada al momento de la ocupación final del distrito. Hoy el pantano del Negratín impide ver la vega que tenía por debajo de la elevación en donde se sitúa la estructura defensiva de la que quedan algunos restos. Parece que el poblado estaba sin amurallar, al lado de los muros que cerraban un pequeño espacio amurallado. Estaba ya muy cerca de Baza.

El último anillo defensivo estaba formado por los asentamientos defendidos de Zújar, que tiene una rica vega regada por un sistema hidráulico que parte de una fuente principal ${ }^{31}$. Era una estructura habitada y amurrallada en una altura sobre un pequeño arroyo. Se halla casi al mismo pie del Jabalcón, elevación montañosa en medio de la hoya de Baza, de la que nos habla el geógrafo al-Zuhri, como un punto en donde sucedían maravillas de la naturaleza ${ }^{32}$.

Más hacia el oeste encontramos Freila, con una pequeña defensa en una elevación sobre el río, que riega una fértil vega. El asentamiento está por encima de la torre, posiblemente integrada en un espacio cercado, lo que nos hace pensar que era un mecanismo defensivo de escasa entidad, aunque efectivo, ya que servía para el control del paso, que se veía fortalecido con algunas atalayas esparcidas por su territorio.

Finalmente, al sur de Baza hay algunas alquerías, como Caniles, que cubren sus espaldas y permiten controlar el paso por esa zona.

31 CANO GARCÍA, Gabriel M., «La vega de Zújar», Cuadernos de Geografía, 9 (1971), pp. 33-51, y, sobre todo, ARREDONDO ARREDONDO, Francisco, Regadíos y pagos de la Vega de Zújar, Granada, 2000.

32 «Después de Sierra Nevada al norte de Baza (Basta) se encuentran los montes de Jabalcón (Yibal al-Itmid) de donde se exporta [antimonio] al Magreb. Este monte está en las estribaciones del monte de Abila, en el que hay una fortaleza llamada Tíscar (Tiskar). Allí suceden cosas maravillosas. Una de ellas la constituye la Hoya de Baza, situada en su ladera oriental: consiste en que nadie puede alcanzarla ni por arriba ni por abajo. Cuando sopla el viento de Levante, sale de ella un vapor denso más blanco que la nieve y, cuando sopla en ella el viento del Oeste, sale un humo rojo como la llama del fuego. Al soplar el viento del Sur, exhuma un vapor amarillo como los rayos del sol y, al soplar el del Norte, sale un vapor tan azul como el lapislázuli. Si no le da ningún viento, no sale nada y esto sucede desde tiempos remotos» (BRAMÓN, Dolores, El mundo en el siglo XII. Estudio de la versión castellana y del "Original" Árabe de una geografía universal: "El tratado de al-Zuhri”, Barcelona, 1991, p. 171). 
La ciudad de Baza era el centro de ese subconjunto, pero con otros más o menos relacionados con ella. No vamos a estudiarla en el presente trabajo, pues sería preciso establecer más elementos que ahora no podemos acometer. Baste con señalar que estaba dividida en tres áreas bien diferenciadas: la alcazaba, en la parte superior, la ciudad propiamente dicha y arrabales, amurallados y no defendidos. El tráfico comercial de la estructura urbana era importante y tenía salida incluso hacia el mar siguiendo el valle del Almanzora.

La frontera no generaba sólo mecanismos defensivos, sino también múltiples relaciones. Entre ellas las que permitían el paso del ganado del lado castellano al nazarí para disfrutar de los pastos que permitían que hubiese numerosos animales comiendo sus hierbas y bebiendo sus aguas. Esta relación no acababa con la ganadería, sino que se veía fortalecida con las explotaciones salineras en el piedemonte de las montañas septentrionales. Tanto las de la Sierra de Quesada como las de la parte murciana de la Sierra de Segura jugaron un papel esencial, que habrá que estudiar a fondo en cada caso.

En suma, el territorio regido por Baza y, especialmente, el subconjunto central, se organizaba a partir de la economía agrícola basada en la irrigación, de manera que los núcleos habitados, las alquerías y michares seguramente, se beneficiaban de los recursos hídricos que permitían cultivos intensivos y continuados, pero también se sembraron tierras no irrigadas, sobre todo con cereales, en cañadas y pequeñas hoyas, tanto para alimento de las personas, como para los animales. Estos comían en las rastrojeras y en los baldíos fruto de la rotación aplicada. Los pastos de la llanura, que a veces incluso eran en pequeños puntos irrigados, siendo prados, servían para invernar, en tanto que las hierbas frescas de la montaña eran comidas en el verano. La sal llegaba de las salinas organizadas en explotaciones controladas fiscalmente, muchas de ellas en manos castellanas, pero también de alguna, como la de Bácor, en el altiplano, y de los criptohumedales que daban lugar a saladares (El Margen, El Baíco, etc.).

En resumen, una economía agroganadera mucho más compleja de lo que cabría pensar, a no ser que entremos en el interior de este territorio, lo estudiemos y recorramos palmo a palmo como estamos haciendo. 